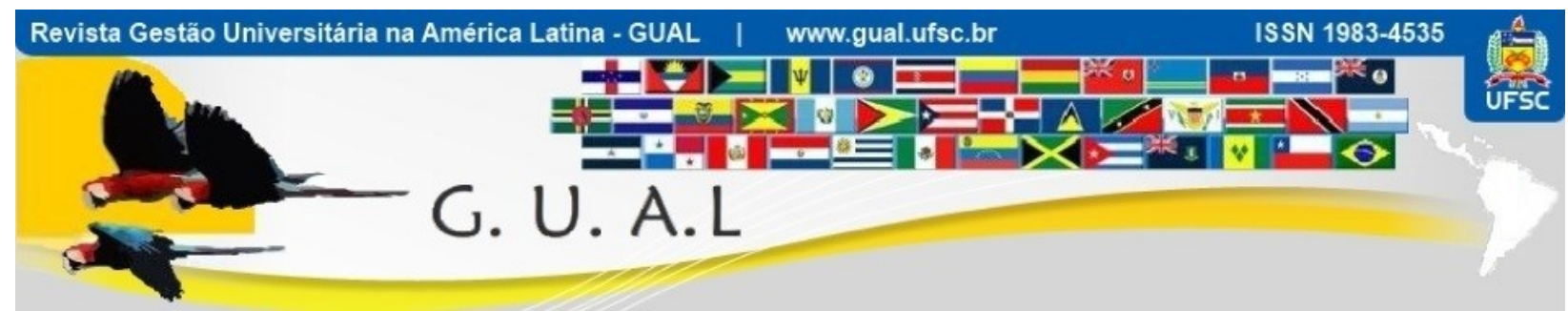

DOI: http://dx.doi.org/10.5007/1983-4535.2017v10n2p1

\title{
ESTRATÉGIAS COMPETITIVAS EM INSTITUIÇÕES DE ENSINO SUPERIOR: UM ESTUDO DE CASO Å LUZ DA VISÃO BASEADA EM RECURSOS
}

\section{COMPETITIVE STRATEGIES IN HIGHER EDUCATION INSTITUTIONS: A CASE STUDY IN THE LIGHT OF RESOURCE BASED VIEW}

David Rodrigo Petry, Doutorando

Universidade do Oeste de Santa Catarina - UNOESC david.petry@unoesc.edu.br

Darlan José Roman, Doutor Universidade do Oeste de Santa Catarina - UNOESC darlan.roman@unoesc.edu.br

Citania Aparecida Pilatti, Mestre Universidade do Oeste de Santa Catarina - UNOESC citaniapilatti@hotmail.com

Carolini Danieli Martins Scheffer Demeterko, Mestre Universidade do Oeste de Santa Catarina - UNOESC carolini@sc.sebrae.com.br

Ieda Margarete Oro, Doutora Universidade do Oeste de Santa Catarina - UNOESC ieda.oro@unoesc.edu.br

Recebido em $02 /$ setembro/2015

Aprovado em 12/dezembro/2016

Sistema de Avaliação: Double Blind Review

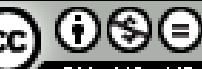

Esta obra está sob uma Licença Creative Commons Atribuição-Uso. 


\title{
RESUMO
}

Este estudo buscou evidenciar os recursos utilizados por uma instituição de ensino superior na busca da vantagem competitiva, com base nos preceitos da visão baseada em recursos. Tratase de um estudo de caso aplicado em uma Instituição de Ensino Superior localizada em Santa Catarina. A coleta de dados foi realizada por meio da aplicação de questionários estruturados aos coordenadores de curso da instituição e utilizadas conjuntamente com resultados obtidos por meio de uma entrevista semiestruturada realizada com o vice-reitor. A pesquisa retornou os recursos de capital físico, humano e organizacional que a instituição atualmente utiliza na busca de sua competitividade, dentre eles, sua estrutura financeira, especialização do corpo docente e o modelo de gestão implementado, assim como possibilitou evidenciar fatores e recursos que podem ser aprimorados e utilizados para aumentar ainda mais sua competitividade no mercado.

Palavras-chave: Competitividade. Instituição de ensino superior. Visão baseada em recursos.

\begin{abstract}
This study sought to highlight the resources used by an institution of higher education in the pursuit of competitive advantage, based on the precepts of the resource-based view. This is a case study applied in a higher education institution located in Santa Catarina. Data collection was performed through structured questionnaires, responded to the institution's course coordinators and used in conjunction with results obtained using a semi-structured interview with the vice-chancellor. Your search returned the resources of physical, human and organizational capital that the institution currently uses in the search for competitiveness, among them, its financial structure, specialization of the faculty and the management model implemented as well as possible evidence factors and resources that can be enhanced and used to further enhance their market competitiveness.
\end{abstract}

Keywords: Competitiveness. Institution of higher education. Resource based view. 


\section{INTRODUÇÃO}

Com a modernização das práticas organizacionais que ano após ano vêm sendo aprimoradas, as organizações vêm sentindo a necessidade de acompanhar essas melhorias visando manterem-se atualizadas. Toda essa movimentação passou a instigar a necessidade das organizações tornarem-se mais competitivas no mercado em que atuam.

Nassif e Hanashiro (2002) destacam que o conceito de competitividade remonta a um passado longínquo, no entanto, com uma progressiva abertura dos mercados internacionais e um avanço na desregulamentação de alguns setores da atividade econômica, novos componentes passaram a disputar na arena competitiva brasileira. Assim, a melhoria da competitividade empresarial impõe-se como uma questão inexorável de sobrevivência das organizações, de qualquer natureza e porte.

Surge então a competitividade sendo utilizada em instituições de ensino superior, no intuito de promover o conhecimento nas organizações, o que acabou convergindo para o conceito de gestão do conhecimento que encontrou apoio tanto no ambiente acadêmico quanto no empresarial.

Neste contexto, surgiu a oportunidade de estudar a utilização da competitividade no ambiente acadêmico, o que deu subsídios para elaboração do objetivo deste estudo, que trata de identificar os recursos utilizados por uma instituição de ensino superior de Santa Catarina, na busca em obter vantagem competitiva, analisando-os à luz da teoria da Visão Baseada em Recursos.

Este estudo torna-se relevante pelo fato de a instituição de ensino superior utilizada no estudo não ter como objetivo a lucratividade, visto ser entidade sem fins lucrativos, o que permite visualizar que a competitividade pode ser alcançada mesmo em condições distintas das organizações que tem por finalidade o lucro.

Este estudo encontra-se estruturado da seguinte maneira: esta seção apresenta a introdução aos temas que são abordados no estudo; a segunda seção traz constructos teóricos sobre estratégia competitiva em Instituições de Ensino Superior e a utilização da teoria da Visão Baseada em Recursos como elo de apoio à pesquisa; a terceira seção dispõe a metodologia utilizada na aplicação do estudo; na quarta seção são discutidos os resultados obtidos por meio da pesquisa de campo; e por fim, a quinta seção apresenta as conclusõesda pesquisa. 


\section{ESTRUTURA CONCEITUAL DE ESTRATÉGIA COMPETITIVA EM INSTITUIÇÕES DE ENSINO SUPERIOR}

Com objetivo de identificar os recursos utilizados por uma Instituição de Ensino Superior (IES) na busca da vantagem competitiva, esta seção visa embasar algumas teorias que vieram se moldando no decorrer do tempo, sendo que inicia-se a seção apresentando o que é e como se formam estratégias competitivas, enquanto na segunda parte fundamenta-se a utilização da competitividade nas Instituições de Ensino Superior, e se encerra a seção trazendo o estudo sobre a teoria da Visão Baseada em Recursos.

\subsection{ESTRATÉGIAS COMPETITIVAS}

Por meio do estudo sobre estratégias competitivas é possível verificar que o tema vem sendo estudado no meio acadêmico há algumas décadas. Verificou-se que com o decorrer do tempo, diversos conceitos importantes vieram se moldando, e colaborou para aproximar as instituições de ensino superior do mercado. Devido aos processos de mudança da economia em termos de competitividade, as instituições passaram a implantar estratégias que proporcionem um nível de competitividade capaz de gerar resultados diferenciados e sustentáveis frente às necessidades de sobrevivência das organizações.

Mintzberg et al (2006) estudou profundamente os conceitos e a evolução de como se criam estratégias competitivas, e entende que a palavra estratégia é baseada em cinco alicerces, que ele mesmo os chama de "5P's": plano, pretexto, padrão, posição e perspectiva. $\mathrm{O}$ autor destaca ainda que toda estratégia é um plano, uma diretriz ou um conjunto de diretrizes para lidar com uma situação. Assim como plano, uma estratégia também pode ser um pretexto, uma manobra específica para superar um oponente ou concorrente. Porém definir estratégia como um plano não é suficiente, desta forma estratégia é um padrão em uma corrente de ações. Também definimos a estratégia como uma posição tornando-se a força mediadora entre organização e ambiente, ou seja entre o contexto interno e o externo. Porém ao definir estratégia como uma perspectiva, temos uma visão mais ampla para dentro da organização. Nesta quinta definição de estratégia é importante destacar que a perspectiva é compartilhada pelos membros de uma organização, por suas intenções e/ou por suas ações.

Quinn (1980) definiu estratégia como sendo um padrão ou plano que integra as principais metas, políticas e sequências de ação da organização em um todo coeso. Uma estratégia bem formulada ajuda a organizar e alocar os recursos de uma organização em uma 
postura única e viável, baseada em suas competências e deficiências internas relativas, mudanças antecipadas no ambiente e movimentos contingentes por parte dos oponentes inteligentes. Desta forma as decisões estratégicas são as que definirão o caminho da empresa, com base nas características do ambiente externo incluindo os competidores, e do ambiente interno com a alocação eficiente de recursos disponíveis nas empresas.

Estratégia competitiva é a escolha de um conjunto de atividades diferentes para entregar um mix único de valores, ou seja, um mix diferenciado. Porter e Kramer (2006) destacam que as estratégias competitivas surgem de três fontes distintas que são mutuamente exclusivas e sempre se sobrepõem. A primeira delas é o posicionamento baseado em variedade, o qual é fundamentado na escolha das variedades de produto ou serviço, e não em segmentos de cliente. Isso significa que a empresa pode produzir melhor determinados produtos ou serviços usando conjuntos de atividades diferentes. Já por outro lado podemos ter o posicionamento estratégico baseado em necessidade, que surge quando há grupos de clientes com necessidades diferentes e há um conjunto de atividades especificas para melhor atender estes grupos seletos. Por último a terceira base é o posicionamento baseado em acesso, onde o acesso pode ser definido em função da geografia do cliente ou da escala do cliente (PORTER; KRAMER, 2006). O autor define ainda estratégia como sendo a criação de uma posição de valor e única, envolvendo um conjunto de atividades diferentes e que a essência do posicionamento estratégico é escolher atividades que sejam diferentes das atividades dos rivais.

As breves explanações apresentadas vêm a iniciar os debates sobre a competitividade, cujo teor será mais aprofundado na seção a seguir, que trata de sua utilização em Instituições de Ensino Superior.

\subsection{COMPETITIVIDADE EM INSTITUIÇÕES DE ENSINO SUPERIOR}

Diversas formas de buscar maior competitividade vêm sendo almejadas pelas organizações em busca de seu lugar no mercado. Niskier (1996) afirma que algumas buscam aperfeiçoar-se nos processos burocráticos, outras investem em sua infraestrutura organizacional, e há ainda quem dispensa tais prerrogativas e foca no ensino como essência de seu negócio.

Podem ainda ser consideradas como maneiras de aumentar a competitividade no mercado, a implantação de sistemas de controle e investimentos em tecnologia. Porém, a 
evolução sócio-organizacional que a sociedade pós-moderna vem sofrendo faz com que as organizações passem a adotar mudanças e diferenciais no critério de valorização da mão-deobra. A exigência dessa valorização faz com que a formação do aprendizado torne-se, dentre todas as demais fontes de competitividade nas instituições de ensino superior, o instrumento mais importante para alcançá-la (OLIVA; ROMAN; MAZZALI; 2010).

Nassif e Hanashiro (2002) afirmam que a capacitação e qualificação dos professores vêm emergindo como palavra de ordem, destacando a necessidade de o profissional rever e desenvolver competências para acompanhar a demanda de informações, atentar para a introdução de novas tecnologias, estar presente e fazer parte do mundo dos jovens e ser parte integrante do processo de mudança instalado no setor educacional.

Neste contexto surge a figura da universidade corporativa, que, segundo Vergara (2000) são organizações que ensinam a praticar, diferentemente das tradicionais, que em tese, ensinam a estudar e a pesquisar. Éboli (2004) complementa dizendo que as unidades de educação corporativa são sistemas de desenvolvimento de pessoas pautados pela gestão alicerçada em competências.

Marcovitch (1998) destaca que não existe universidade ou instituição de ensino superior perfeitas, e enfatiza que é próprio do pensamento acadêmico enxergar o real como algo incompleto, que sempre exigirá aperfeiçoamento contínuo. Há ainda a necessidade de repensar os papéis e as funções do ensino superior, o papel dos educadores e os procedimentos acadêmicos e administrativos como um todo devido ao crescimento e à importância que a educação representa para o mercado de trabalho. Estas mudanças estão galgadas em políticas institucionais e governamentais e em pesquisa dentro das instituições, o que permite detectar a fragilidade do sistema educacional como um todo (NISKIER,1996).

Um fator muito importante para a competitividade em universidades é a diversificação da oferta de cursos, estrutura, organização e implementação do processo, bem como a qualidade do produto ofertado como meios para produzir e difundir conhecimentos, visando formar profissionais qualificados para o mercado de trabalho, promover a cultura, a ciência e a tecnologia e assegurar serviços de qualidade à sociedade (TRAMONTIN,1998).

Dentre as ações apontadas, apesar de colaborarem para o aumento da competitividade, nenhuma garante à instituição aumento da mesma e a obtenção de parcela do mercado, visto que referidos processos podem ser facilmente copiados pela concorrência. Pfeffer (1994) aponta que uma fonte de vantagem competitiva que possa efetivamente trazer benefícios 
diante do mercado, é o gerenciamento de pessoas, pois formam sistemas integrados difíceis de serem imitados pela concorrência.

O alinhamento da oferta de programas educacionais de qualidade e de disponibilização de colaboradores que detém o conhecimento necessário para reproduzir o conhecimento com qualidade, faticamente apresenta-se como a essência da vantagem competitiva sustentável em instituições de ensino superior (NURMI, 1998). Sustentabilidade, neste sentido, refere-se à necessidade de as instituições obrigarem-se a utilizar suas próprias fontes de receitas, assumindo-se como unidades de negócios geradoras de resultados procurando agregar valor e reinvestindo seus ganhos na melhoria da qualidade educacional e estrutural da universidade.

Diante da estrutura teórica sobre competitividade nas instituições de ensino superior, a seção seguinte apresenta brevemente alguns dispositivos teóricos sobre a visão baseada em recursos $(\mathrm{RBV})$.

\subsection{VISÃO BASEADA EM RECURSOS}

A Visão baseada em Recursos - VBR (RBV - em inglês) surgiu da frustração com o paradigma da Visão da Organização Industrial (OI). Enquanto a Organização Industrial tinha como base de sua teoria que o sucesso empresarial era gerado por meio de fatores externos à organização, a RBV contraria esta teoria e constrói outra em torno das competências internas da empresa (PORTER, 1980; WERNERFELT, 1984; PRAHALAD E HAMMEL, 1990).

A RBV, como o próprio nome diz, tem como base a utilização de recursos na busca da vantagem competitiva. Daft (1983) afirma que os recursos são os ativos, capacidades, processos organizacionais, atributos da empresa, informação, conhecimento, entre outros fatores, que são controlados pela empresa as quais a permitem criar e implementar melhorias na eficiência e eficácia da organização. Porter (1991) complementa dizendo que esses recursos são os pontos fortes que podem ser utilizados na melhoria de suas estratégias de competitividade.

Os recursos de uma empresa podem ser segmentados em dois tipos: recursos tangíveis e recursos intangíveis. Russo e Fouts (1997, p.537, tradução nossa) tratam os recursos tangíveis como sendo as "reservas financeiras e os recursos físicos, tais como instalações, equipamentos e estoques de matérias-primas", já os recursos intangíveis "incluem reputação, tecnologia e recursos humanos; este último incluir a cultura, a formação e especialização de funcionários, e seu compromisso e lealdade" (RUSSO; FOUTS; 1997, p.537, tradução nossa). 
Barney (1991) destaca que nem todos os aspectos de capital físico, humano e organizacional são recursos relevantes à competitividade das organizações. Afirma que alguns destes atributos podem impedir a empresa de criar e implementar estratégias valiosas, que podem reduzir sua eficácia e eficiência e ainda podem não ter impacto sobre as estratégias da empresa. Por este motivo, é necessário que as empresas identifiquem e selecionem os recursos que melhorem sua eficácia e eficiência, para que estes possam ampliar o campo competitivo organizacional.

A utilização dos recursos que a empresa possui sempre está relacionada à busca pela vantagem competitiva sustentável. Mas para que sirva como fator de competitividade, os recursos necessariamente devem ter quatro atributos essenciais. Barney (1991) afirma que para ser competitivo, o recurso deve ser: (a) valioso, pois deve aproveitar-se das oportunidades, explorando-as e buscando neutralizar possíveis ameaças que permeiam as organizações, (b) raro, visando afastar potenciais concorrentes, (c) imperfeitamente imitável, no sentido de utilizar-se de condições históricas únicas e socialmente complexas, dificultando novos entrantes e, (d) organizável, de forma que a empresa possa explorar o potencial raro e valioso de seus recursos, impedindo que sejam substituídos por elementos alternativos.

Pavão, Sehnem e Hoffmann (2011) complementam dizendo que os recursos raros e valiosos, só poderão ser fonte de vantagem competitiva se as empresas que não os detêm possuem alguma desvantagem com relação ao custo para obtê-los ou desenvolvê-los, comparadas às empresas que já os possuem. A utilização desses atributos como forma de estratégia competitiva compreende o modelo VRIO, que de acordo com Barney (1991) fundamenta-se em uma ferramenta que identifica forças e fraquezas internas à organização.

A teoria da visão baseada em recursos não explica como determinadas empresas têm vantagem competitiva em situações de imprevisíveis mudanças, quando comparadas à outras, onde principalmente em mercados de rápidas mudanças, as capacidades dinâmicas possibilitam às firmas reconfigurarem suas competências de acordo com as mudanças no ambiente (TEECE, 2007).

Grant (1991) afirma que as mudanças no ambiente organizacional são oportunidades às empresas, pois os recursos e as capacidades proporcionam uma base mais estável para definir sua missão e visão estratégica, ou seja, atuam com intuito de satisfazer as necessidades dos clientes. Itami (1994) também aponta que a estratégia deve ser moldada pelos fatores externos (clientes, concorrentes e tecnologia), porém, para que a empresa possa utilizar-se dos 
fatores externos à organização em busca da vantagem competitiva, necessita primeiramente que esteja bem articulada internamente e estar ciente de que são o nível de recursos e o clima organizacional que irão determinar sua capacidade de adaptação e inovação.

Nessa linha de raciocínio, Eisenhardt e Martin (2000) destacam que a vantagem competitiva não é sustentável em ambientes turbulentos, pois o desempenho superior advém de vantagens históricas e temporárias, e que são inovadas continuamente. Destacam ainda que essa habilidade de buscar inovações para manter a vantagem competitiva são denominadas Capacidades Dinâmicas.

Criar capacidades não é simplesmente uma questão de reunir recursos (GRANT, 1991). O autor destaca ainda que as capacidades envolvem complexos padrões de coordenação entre pessoas, e entre pessoas e outros recursos. Diante disso, pode-se citar as rotinas organizacionais como um bom exemplo, pois são padrões de atividades regulares e previsíveis que resultam de uma sequencia coordenada de ações individuais. À medida que esses recursos e capacidades específicos da organização geram benefícios econômicos e não podem ser perfeitamente duplicados pelos competidores eles passam a tornar-se fontes de vantagem competitiva sustentável (AMIT; SCHOEMAKER, 1993; BARNEY, 1991).

Diante da fundamentação exposta, a seção seguinte apresenta a metodologia da aplicação do estudo de caso aplicado em uma Instituição de Ensino Superior, trazendo em seu escopo a abordagem da pesquisa, as técnicas de coleta de dados, dentre outros aspectos relacionados à pesquisa.

\section{METODOLOGIA}

Esta pesquisa apresenta um estudo teórico-empírico, realizado por meio de uma abordagem de pesquisa qualitativa, descritiva e estudo de caso. Vergara (1997) destaca que para um estudo apresentar adequadamente sua metodologia buscando alcançar os fins pretendidos, a mesma pode ser realizada de acordo com os meios e os fins adequados ao escopo do universo em que ela se enquadra. Esta pesquisa pode ser caracterizada como sendo um estudo de caso, pois trata-se de um estudo aplicado em apenas uma instituição de ensino superior localizada em Santa Catarina.

Quanto aos fins, este estudo classifica-se como sendo descritivo, pois tem a intenção de identificar e descrever os recursos utilizados em busca da competitividade. Hair Jr. e Joseph F. (2005) destacam que em geral os planos de pesquisa descritivos são estruturados e 
especificamente criados para medir as características descritas em um problema de pesquisa. Dessa forma, a coleta de dados utilizada é a entrevista estruturada e a utilização de questionários contendo itens específicos visando responder aos objetivos propostos.

Triviños (1987) complementa afirmando que o estudo descritivo exige do pesquisador uma delimitação correta de técnicas, métodos, modelos e teorias que norteiam a coleta e a interpretação dos dados, visto que o objetivo deste modelo é conferir validade científica à pesquisa.

A caracterização da pesquisa quanto à metodologia e conteúdo empregado é qualitativa, pois inclui, de acordo com Cooper e Schindler (2011), um conjunto de técnicas interpretativas que procuram descrever, decodificar, traduzir e, de outra forma, apreender o significado, e não a frequência, de certos fenômenos ocorrendo de forma mais ou menos natural no mundo social. Os autores complementam dizendo que as técnicas qualitativas são usadas nos estágios de coleta e análise de dados de um projeto de pesquisa.

Roesch (2012) afirma ainda que a pesquisa qualitativa é apropriada para a avaliação formativa, quando se trata de melhorar a efetividade de um programa, ou plano, ou mesmo quando é o caso da proposição de planos, ou seja, quando se trata de selecionar as metas de um programa e construir uma intervenção, mas não é adequada para avaliar resultados de programas ou planos.

A coleta de dados se deu por meio de aplicação de um questionário destinado aos coordenadores de cursos de uma instituição de ensino superior de Santa Catarina. O questionário aplicado, adaptado dos estudos de Pavão, Sehnem e Hoffmann (2011), foi encaminhado via e-mail e buscou identificar a percepção dos respondentes com relação aos recursos competitivos que a instituição possui. A pesquisa contou ainda com a realização de uma entrevista com o vice-reitor de campus, realizada pessoalmente, com duração de aproximadamente uma hora, foi gravada para melhor tratamento dos dados coletados, e contribuiu qualitativamente para identificar os recursos utilizados.

A análise dos dados foi realizada mediante estatística descritiva simples das respostas dos questionários e comparada ainda com os dados coletados por meio da entrevista.

Diante do exposto, a seção seguinte apresenta os dados e as discussões das informações coletadas na instituição de ensino selecionada para o estudo. 


\section{ANÁLISE DOS DADOS - ESTUDO DE CASO}

Este estudo tem como objetivo identificar os recursos utilizados por uma instituição de ensino superior de Santa Catarina, na busca em obter vantagem competitiva, analisando-os à luz da teoria da Visão Baseada em Recursos. Para que fosse possível alcançar os resultados esperados, optou-se em dividir a coleta de dados em duas seções. A primeira tratou de coletar dados por meio de questionários aplicados aos coordenadores de curso da instituição, e a segunda parte utilizou-se da aplicação de uma entrevista ao vice-reitor de campus, cujos resultados coletados podem ser verificados na sequência deste estudo.

A coleta de dados aos coordenadores de curso utilizou-se de questionário voltado a identificar os recursos valiosos, raros, inimitáveis e organizáveis, conforme fundamentado no início do estudo. O questionário apresentou-se dividido em três grupos de recursos, sendo eles, Recursos de Capital Físico, Recurso de Capital Humano e Recurso de Capital Organizacional, segregados para melhor identificar quais podem ser considerados no modelo VRIO.

Foi solicitado aos respondentes que marcassem com " $x$ ", qual o valor que cada item questionado representa para a instituição hoje, utilizando uma escala de um a dez, sendo um para o menor grau $(1=$ péssimo $)$ e dez para o maior grau $(10=$ excelente $)$.

Após coletados, os dados foram tabulados e realizada estatística descritiva simples buscando identificar para cada pergunta do questionário a média, a mediana, o desvio padrão, o coeficiente de variação e a variância de cada uma delas. Os resultados da estatística descritiva simples dos Recursos de Capital Físico da instituição analisada encontram-se dispostos na Tabela 1.

Calculou-se a média e a mediana dos dados coletados buscando encontrar o ponto de equilíbrio das frequências, ou seja, onde mais se concentram os valores apresentados pelos respondentes. O desvio padrão representa o índice de dispersão de cada variável, enquanto o coeficiente de variação e a variância representam quão longe em geral os dados se encontram em relação à média encontrada. Para fins de análise do grau de possibilidade de os aspectos serem considerados recursos valiosos, raros, inimitáveis e organizáveis, tomou-se como parâmetro: média $<8=$ insuficiente para ser VRIO; entre 8 e $9=$ com melhorias pode tornarse VRIO; e média $>9$ = tendência em ser VRIO. 
Tabela 1 Avaliação dos aspectos referente aos Recursos de Capital Físico.

\begin{tabular}{|c|c|c|c|c|c|}
\hline ASPECTOS AVALIADOS & MÉDIA & MEDIANA & $\begin{array}{l}\text { DESVIO } \\
\text { PADRÃO } \\
\end{array}$ & $\begin{array}{c}\text { COEF. } \\
\text { VARIAÇÃ̃O }\end{array}$ & VARIÂNCIA \\
\hline 1. Localização geográfica & 7,71 & 8,00 & 1,98 & 25,62 & 3,90 \\
\hline 2. Produtos da instituição (cursos) & 8,29 & 8,00 & 1,38 & 16,66 & 1,90 \\
\hline 3. Equipamentos da instituição & 8,86 & 9,00 & 0,90 & 10,16 & 0,81 \\
\hline $\begin{array}{l}\text { 4. As tecnologias adotadas nos } \\
\text { processos de serviços prestados }\end{array}$ & 8,71 & 9,00 & 1,11 & 12,77 & 1,24 \\
\hline $\begin{array}{l}\text { 5. O nível de desempenho dos } \\
\text { recursos investidos na instituição }\end{array}$ & 8,86 & 9,00 & 0,69 & 7,79 & 0,48 \\
\hline 6. O acesso aos clientes & 8,57 & 9,00 & 1,27 & 14,84 & 1,62 \\
\hline $\begin{array}{l}\text { 7. As tecnologias de hardware e } \\
\text { software }\end{array}$ & 8,43 & 9,00 & 0,79 & 9,33 & 0,62 \\
\hline $\begin{array}{l}\text { 8. O nível de qualidade dos cursos } \\
\text { em relação aos concorrentes }\end{array}$ & 9,43 & 10,00 & 0,79 & 8,34 & 0,62 \\
\hline $\begin{array}{l}\text { 9. A agilidade do processo de } \\
\text { implementação de novos cursos }\end{array}$ & 8,57 & 8,00 & 1,13 & 13,23 & 1,29 \\
\hline $\begin{array}{l}\text { 10. O nível de produtividade da } \\
\text { instituição }\end{array}$ & 8,14 & 8,00 & 1,86 & 22,90 & 3,48 \\
\hline 11. Qualidade da ementa dos cursos & 8,00 & 8,00 & 1,15 & 14,43 & 1,33 \\
\hline $\begin{array}{l}\text { 12. Os canais de disponibilização dos } \\
\text { cursos (presencial, EAD...) }\end{array}$ & 7,29 & 8,00 & 3,15 & 43,20 & 9,90 \\
\hline $\begin{array}{l}\text { 13. A localização dos docentes em } \\
\text { relação a localização da instituição }\end{array}$ & 7,71 & 8,00 & 1,89 & 24,50 & 3,57 \\
\hline $\begin{array}{l}\text { 14. A localização dos acadêmicos em } \\
\text { relação localização da instituição }\end{array}$ & 7,71 & 8,00 & 0,95 & 12,33 & 0,90 \\
\hline 15. Capacidade de oferta de cursos & 8,71 & 9,00 & 1,11 & 12,77 & 1,24 \\
\hline
\end{tabular}

Fonte: Dados da pesquisa (2015).

Pode-se verificar na Tabela 1 que dentre os 15 itens pesquisados, os aspectos relativos à localização geográfica, canais de disponibilização de cursos, localização dos docentes em relação à instituição e a localização dos acadêmicos em relação à instituição apresentam as médias mais baixas relativas aos recursos físicos da instituição, alcançando média insuficiente para ser considerada valiosa, rara, inimitável e organizável. Somente o item 8 , que trata do nível de qualidade dos cursos apresenta média superior a 9, fator que pode ser considerado entre uma das classes do VRIO. Todas as demais 10 variáveis encontram-se entre 8 e 9, que para caracterizarem-se como VRIO necessitam de melhorias.

Com relação às estatísticas de dispersão, verifica-se que as variáveis localização geográfica, nível de produtividade da instituição e canais de disponibilização de cursos apresentam leve distorção, o que representa uma disparidade entre a percepção dos respondentes com relação à área da instituição em que atuam. 
Por meio da entrevista, foi possível identificar a percepção da alta gestão com relação aos recursos que podem tornar a instituição mais competitiva. Quando questionado quais recursos físicos são mais valiosos e raros para a instituição, o entrevistado responde: "Estrutura financeira vem primeiro e depois a estrutura laboratorial", justificando que o perfil dos alunos que atualmente procura o ensino superior busca conforto, atendimento diferenciado e um atendimento além do que tinham quando estudavam no ensino médio.

Quando questionado quanto aos recursos de difícil imitação na instituição, o entrevistado reafirma que "a condição financeira da instituição é ímpar, de sustentabilidade econômica e financeira. A saúde é única, com uma característica própria, isso no estado de Santa Catarina e não apenas nesta unidade, pela utilização de um modelo de gestão muito racional, baseado em princípios muitas sólidos, por meio de metas e regramentos..."

Questionou-se ao entrevistado se a instituição está organizada para explorar ao máximo o potencial competitivo de seus recursos e capacidades de controle. O entrevistado afirma:

[...] sim, organizada está, mas ela não explora, pois é muito burocrática. As universidades de um modo geral são muito burocráticas e lentas. Lentas na tomada de decisão e esse talvez seja o principal entrave quando comparadas à faculdades que tem apenas um dono que toma a decisão e faz as coisas acontecerem. Uma universidade no modelo que é nossa instituição, que é Multicampi, que depende de conselhos, depende de vários olhares para que se executem os projetos o processo é lento, ele é lento e isso mitiga a possibilidade de competitividade em muitas áreas, como por exemplo na implantação de novos cursos. É muito demorado o processo de implementação deles, tem todo um trabalho de base que tem que ser feito, então isso nos limita. (Dados da pesquisa, 2015)

Encerrando os questionamentos com relação aos Recursos de Capital Físico, questionou-se quais os fatores que contribuem para a instituição obter vantagem competitiva perante as demais universidades da região? O entrevistado responde que "o principal elemento que destaca a universidade é a credibilidade, que vem agregado ao valor que está associado à marca, com o tempo e seriedade da instituição".

Encerrados os debates sobre os dados carreados com relação aos Recursos de Capital Físico da instituição, a Tabela 2 apresenta os resultados coletados pelos questionários com relação aos Recursos de Capital Humano. 
Tabela 2 Avaliação dos aspectos referente aos Recursos de Capital Humano.

\begin{tabular}{|c|c|c|c|c|c|}
\hline ASPECTOS AVALIADOS & MÉDIA & MEDIANA & $\begin{array}{l}\text { DESVIO } \\
\text { PADRÃO }\end{array}$ & $\begin{array}{c}\text { COEF. } \\
\text { VARIAÇÃO }\end{array}$ & VARIÂNCIA \\
\hline $\begin{array}{l}\text { 1. Trabalho em equipe e entre os } \\
\text { gestores da instituição. }\end{array}$ & 9,29 & 9,00 & 0,49 & 5,25 & 0,24 \\
\hline $\begin{array}{l}\text { 2. Os treinamentos oferecidos pela } \\
\text { instituição }\end{array}$ & 8,57 & 9,00 & 1,13 & 13,23 & 1,29 \\
\hline $\begin{array}{l}\text { 3. Os recursos humanos } \\
\text { (funcionários da instituição). }\end{array}$ & 8,43 & 9,00 & 0,98 & 11,58 & 0,95 \\
\hline $\begin{array}{l}\text { 4. O conhecimento técnico e } \\
\text { científico. }\end{array}$ & 8,43 & 8,00 & 0,98 & 11,58 & 0,95 \\
\hline $\begin{array}{l}\text { 5. As rotinas para desenvolver as } \\
\text { atividades no dia-a-dia. }\end{array}$ & 8,00 & 8,00 & 1,29 & 16,14 & 1,67 \\
\hline $\begin{array}{l}\text { 6. A agilidade do processo de } \\
\text { compra de insumos. }\end{array}$ & 8,14 & 8,00 & 0,90 & 11,05 & 0,81 \\
\hline $\begin{array}{l}\text { 7. A qualidade dos serviços } \\
\text { prestados aos clientes. }\end{array}$ & 8,57 & 9,00 & 0,98 & 11,39 & 0,95 \\
\hline $\begin{array}{l}\text { 8. O suporte e atendimento ao } \\
\text { consumidor. }\end{array}$ & 8,57 & 9,00 & 0,98 & 11,39 & 0,95 \\
\hline 9. O suporte aos distribuidores. & 8,57 & 9,00 & 0,79 & 9,18 & 0,62 \\
\hline
\end{tabular}

Fonte: Dados da pesquisa (2015).

Analisando a Tabela 2 pode-se verificar que nenhuma média ficou menor que 8 , e assim como nos Recursos de Capital Físico, somente uma variável classificou-se acima de 9, o trabalho em equipe e entre os gestores da instituição. Todas as demais variáveis classificaram-se entre 8 e 9. Quanto aos índices de dispersão, nota-se que nenhuma variável apresenta desvio padrão, coeficiente de variação e variância fora do normal.

$\mathrm{Na}$ entrevista, quando questionado quais Recursos de Capital Humano são mais valiosos para a instituição, o entrevistado afirma que é a: “Capacitação permanente, pois como nosso produto final é a educação, nós temos a obrigação de investirmos. Você abrir mão da qualificação permanente, do técnico administrativo, especialmente do corpo docente é você abrir mão da essência do que é ser uma universidade". O entrevistado complementa ainda dizendo que "para que isso seja possível, a universidade investe em programas específicos para os professores, com ajuda de custo, [...] a universidade toma muito cuidado para atender os critérios exigidos pelo MEC, e onde ela não consegue atender objetivamente no momento esses critérios, ela incentiva à qualificação: mestrado, doutorado e outras áreas".

Quando questionado quanto aos recursos raros de capital humano o entrevistado afirma que os docentes podem ser considerados raros, pois vão agregando conhecimentos que depois vai retornar na qualidade do ensino. Para conseguir reter esta mão de obra, a universidade dispõe de um processo de credenciamento interno que valoriza a carga horária e permite estabilidade financeira para que possam ter uma posição tranquila. Com relação à 
retenção, o entrevistado complementa: “[...] existe um processo de aglutinação de carga horária, então a pessoa que tem mais tempo, e já tem credenciamentos, tem preferência para completar a sua carga horária e o que sobra vai para os outros".

Outra pergunta realizada ao entrevistado foi: Quais recursos são difíceis de a concorrência imitar? Ele responde afirmando que:

“o conceito de imitação sobre a ótica estratégica é um pouco dúbio de entendimento, porque imitação sugere você imitar um produto com o mesmo desempenho. Em educação você nunca vai ter dois produtos com desempenho similar, ainda que sejam dois cursos de administração o desempenho de um do outro sempre vai ser diferente. Então, o que é impossível de imitar é o valor agregado a marca e a diferenciação na qualidade dos cursos oferecidos". (Dados da pesquisa, 2015).

Quando questionado se a instituição está organizada para utiliza-se dos recursos de capital humano, o entrevistado afirma que não, mas que a instituição vem se estruturando e melhorando seus processos justamente e principalmente para reter a mão de obra qualificada, que é fundamental para a competitividade em uma instituição de ensino superior.

Realizada a análise com relação aos Recursos de Capital Humano, passamos a tratar sobre os Recursos de Capital Organizacional. A Tabela 3 apresenta o resultado da aplicação do questionário para os coordenadores de curso da instituição.

Tabela 3 Avaliação dos aspectos referente aos Recursos de Capital Organizacional.

\begin{tabular}{|c|c|c|c|c|c|}
\hline ASPECTOS AVALIADOS & MÉDIA & MEDIANA & $\begin{array}{l}\text { DESVIO } \\
\text { PADRÃOO }\end{array}$ & $\begin{array}{c}\text { COEF. } \\
\text { VARIAÇÃO }\end{array}$ & VARIÂNCIA \\
\hline $\begin{array}{l}\text { 1. Nível de reputação da instituição } \\
\text { entre os clientes. }\end{array}$ & 9,29 & 10,00 & 0,95 & 10,24 & 0,90 \\
\hline $\begin{array}{l}\text { 2. A cooperação existente entre as } \\
\text { funções de criação, técnica e } \\
\text { comercial. }\end{array}$ & 8,86 & 9,00 & 1,07 & 12,07 & 1,14 \\
\hline $\begin{array}{l}\text { 3. A competência de marketing da } \\
\text { instituição. }\end{array}$ & 7,86 & 9,00 & 2,41 & 30,68 & 5,81 \\
\hline $\begin{array}{l}\text { 4. As tecnologias de hardware e } \\
\text { software. }\end{array}$ & 8,43 & 9,00 & 0,79 & 9,33 & 0,62 \\
\hline $\begin{array}{l}\text { 5. Os sistemas formais e informais } \\
\text { de planejamento. }\end{array}$ & 8,14 & 9,00 & 1,68 & 20,58 & 2,81 \\
\hline $\begin{array}{l}\text { 6. Sistemas de controle da } \\
\text { instituição. }\end{array}$ & 7,86 & 9,00 & 1,57 & 20,03 & 2,48 \\
\hline $\begin{array}{l}\text { 7. Sistemática de coordenação das } \\
\text { atividades na instituição. }\end{array}$ & 8,71 & 9,00 & 0,95 & 10,92 & 0,90 \\
\hline 8. A marca da instituição. & 9,71 & 10,00 & 0,49 & 5,02 & 0,24 \\
\hline $\begin{array}{l}\text { 9. O nível de sofisticação tecnológica } \\
\text { em relação aos seus concorrentes. }\end{array}$ & 8,71 & 9,00 & 1,25 & 14,39 & 1,57 \\
\hline $\begin{array}{l}\text { 10. A capacidade de inovação da } \\
\text { instituição. }\end{array}$ & 8,43 & 9,00 & 1,81 & 21,51 & 3,29 \\
\hline 11. Comunicação externa. & 7,86 & 9,00 & 2,04 & 25,91 & 4,14 \\
\hline 12. Comunicação interna. & 8,43 & 9,00 & 1,40 & 16,58 & 1,95 \\
\hline
\end{tabular}

Fonte: Dados da pesquisa (2015). 
A Tabela 3 apresenta três variáveis com média inferiores a 8 com relação aos Recursos de Capital Organizacional, sendo elas, a competência de marketing da instituição, os sistemas de controle a e comunicação externa. De 12 variáveis analisadas, 9 apresentaram-se mais bem colocadas, apresentando médias superiores a 8, com destaque para o nível de reputação da instituição e para a marca da instituição, que apresentam médias superiores a 9, classificandose como potenciais fatores geradores de competitividade.

$\mathrm{Na}$ entrevista, quando questionado com relação a quais recursos organizacionais a instituição caracteriza como sendo valiosos ou raro, o entrevistado afirma:

O modelo de gestão da Universidade em que pese ele tenha esse processo mais lento, ele é um modelo consolidado, pelos resultados que vem apresentando. [...] essa cultura a instituição conseguiu em razão do capital social da própria instituição, que, pela característica da instituição, acaba meio que se blindando aos modelos comuns de gestão. (Dados da pesquisa, 2015).

Com relação à organização da instituição para explorar todo seu capital organizacional, o entrevistado destaca que ainda há muito a ser feito e que hoje não explora esse potencial, e afirma ainda que a tecnologia utilizada pela instituição e constantes investimentos em aprimoramento são fatores que colaboram para a competitividade da universidade.

Finalizando, o entrevistado destaca uma observação com relação à operacionalização e localização, afirmando que:

[...] ainda que nós estejamos em um local privilegiadíssimo, nós estamos fora do grande fluxo populacional, e esse é um problema sério, pois sob a ótica de marketing, as pessoas costumam se estabelecer e frequentar lugares onde o grande fluxo está, e nós estamos paralelos a este fluxo, quase na contra mão. Nós temos o maior concorrente aqui da cidade localizado numa região de 70.000 habitantes. Nós estamos em uma região que não chega nem perto disso. Isso não restringe a vinda de estudantes para a instituição, mas, se estivesse localizada no centro da cidade, nosso desempenho seria muito superior, porque as pessoas que trabalham no centro vão para suas casas nesses bairros populacionais, que está mais próximo da outra instituição, então se nós estivéssemos nessa rota, nós teríamos mais alunos". (Dados da pesquisa, 2015).

Diante das análises dos dados coletados, na sequencia apresenta-se as conclusões do estudo e sugestões de realização de novas pesquisas na área.

\section{CONCLUSÕES}

Este estudo objetivou identificar os recursos utilizados por uma instituição de ensino superior de Santa Catarina, na busca em obter vantagem competitiva, analisando-os à luz da 
teoria da Visão Baseada em Recursos, e alcançou o resultado esperado, como pode ser visualizado no Quadro 1.

\begin{tabular}{|c|c|c|}
\hline $\begin{array}{l}\text { RECURSOS DE CAPITAL } \\
\text { FÍSICO } \\
\end{array}$ & $\begin{array}{c}\text { RECURSOS DE CAPITAL } \\
\text { HUMANO } \\
\end{array}$ & $\begin{array}{r}\text { REC } \\
\text { OF } \\
\end{array}$ \\
\hline $\begin{array}{ll}\text { - } & \text { Estrutura Financeira; } \\
\text { - } & \text { Qualidade dos cursos } \\
\text { ofertados; } \\
\text { - } \quad \text { Credibilidade; } \\
\text { - } \quad \text { Tempo de Mercado; } \\
\text { - } \quad \text { Seriedade da Instituição; } \\
\quad \text { Marca da Instituição; }\end{array}$ & $\begin{array}{l}\text { - } \\
\text { especializado; }\end{array}$ & $\begin{array}{l}\text { - } \quad \text { Modelo de Gestão } \\
\text { aprimorado; } \\
\text { - Tecnologia laboratorial; } \\
\text { - } \quad \text { Constantes investimentos } \\
\text { em processos gerenciais; }\end{array}$ \\
\hline
\end{tabular}

Quadro 1 Quadro resumo de Recursos de Capital utilizados pela Instituição.

Fonte: Dados da pesquisa (2015).

O Quadro 1 destaca o resumo dos recursos utilizados pela instituição na busca da vantagem competitiva. Pode-se verificar que os recursos de capital físico possuem maior presença, devido à maior facilidade em serem alcançados, porém, apesar de os recursos humanos e organizacionais serem mais difíceis de serem alcançados, a instituição consegue barganhar vantagem competitiva nessas esferas.

O estudo tornou-se relevante não somente para identificar quais recursos são explorados atualmente pela instituição, mas também para identificar quais recursos ainda podem ser melhorados. O estudo apresentou limitações no retorno dos questionários, bem como na análise pelo fato de ser aplicado como estudo em uma única instituição. Dessa forma, sugere-se que sejam realizados novos estudos neste molde em outras instituições, podendo até mesmo ser realizado um estudo comparativo, donde acredita-se poder extrair resultados relevantes.

\section{REFERÊNCIAS}

AMIT, R.; SCHOEMAKER, P. J. H. Strategic assets and organizational rent. Strategic Management Journal, v. 14, n. 1, p. 33-46, jan 1993. ISSN 1097-0266. Disponível em: http://business.illinois.edu/josephm/BA545_Fall\%202011/S11/Amit\%20and\%20Schoemaker \%20\%281993\%29.pdf - Acesso em: 03 fev 2015.

BARNEY, J. Firm resources and sustainable competitive advantage. Journal of Management, v. 17, p. 99-120, 1991. ISSN 1557-1211. Disponível em: http://jom.sagepub.com/content/16/2/399 - Acesso em: 11 fev 2015.

COOPER, D. R.; SCHINDLER, P. S. Métodos de Pesquisa em Administração. 10a . ed. São Paulo: Bookman, 2011. 
DAFT, M. J. The influence of mixed inocula on endomycorrhizal development. Plant and Soil, v. 71, p. 331-337, 1983. ISSN 0032-079X. Disponível em: http://link.springer.com/article/10.1007\%2FBF02182672 - Acesso em: 02 fev 2015.

ÉBOLI, M. Educação Corporativa no Brasil: Mitos e Verdades. São Paulo: Editora Gente, 2004.

EISENHARDT, K.; MARTIN, J. Dynamic capabilities: what are they? Strategic Management Journal, n. 21, p. 1105-1121, 2000. ISSN 1097-0266. Disponível em: http://onlinelibrary.wiley.com/doi/10.1002/1097-

0266\%28200010/11\%2921:10/11\%3C1105:AID-SMJ133\%3E3.0.CO;2-E/abstract - Acesso em: 05 fev 2015.

FACHIN, O. Fundamentos de Metodologia. 5a. ed. São Paulo: Saraiva, 2006.

HAIR JR, J. F. et al. Fundamentos de Métodos de Pesquisa em Administração. Porto Alegre: Bookman, 2005.

ITAMI, H. Los activos invisibles. In: CAMPBEL, A.; LUCHS, K.S; Sinergia Estratégica. Bilbao: Deusto, 1994.

MINTZBERG, H. et al. O processo da estratégia: conceitos, contextos e casos selecionados. $4^{\mathrm{a}}$. ed. Porto Alegre: Bookman, 2006.

NASSIF, V. M. J.; HANASHIRO, D. M. M. A competitividade das universidades particulares à luz de uma visão baseada em recursos. Revista de Administração Mackenzie, v. 3, n. 1, p. 95-114, Jan-Jun 2002. ISSN 1678-6971.

NISKIER, A. LDB: a nova lei de educação. Rio de Janeiro: Consultor, 1996.

NURMI, R. Knowledge-intensive firms. Business Horizons, v. 41, p. 26-32, 1998. ISSN 0007-6813.

OLIVA, E.; ROMAN, V.; MAZZALI, L. A universidade corporativa como instrumento de sustentação do negócio. Revista Portuguesa e Brasileira de Gestão, v. 9, p. 75-84, Jun 2010. ISSN 1645-4464.

PAVÃO, I. M. P.; SEHNEM, S.; HOFFMANN, V. E. Análise dos recursos organizacionais que sustentam a vantagem competitiva. Revista de Administração, São Paulo, v. 46, p. 228242, jul-set 2011. ISSN 0080-2107. Disponível em:

www.rausp.usp.br/download.asp?file=v4603228.pdf - Acesso em: 08 fev 2015.

PFEFFER, J. Vantagem competitiva através de pessoas. São Paulo: Makron Books, 1994.

PORTER, M. E. Competitive strategy. Nova York: Free Press, 1980.

PORTER, M. E. Towards a dynamic theory of strategy. Strategic Management Journal, p. 95-117, 1991. ISSN 1097-0266. Disponível em: 
http://ecaths 1.s3.amazonaws.com/fernandoserra/Porter\%20\%281991\%29.pdf - Acesso em: 13 fev 2015.

PORTER, M. E.; KRAMER, M. R. Strategy and society: the link between competitive advantage and corporate social responsibility. Harvard Business Review, p. 78-92, dez 2006.

PRAHALAD, K.; HAMMEL, G. The core competence of the corporation. Harvard Business Review, v. 68, p. 79-91, maio-jun 1990. ISSN 0017-8012. Disponível em:

https://hbr.org/1990/05/the-core-competence-of-the-corporation - Acesso em: 11 fev 2015.

QUINN, J. B. Strategies for Change: Logical Incrementalism. Michigan: R.D. Irwin Inc, 1980 .

ROESCH, S. M. A. Projetos de estágio e de pesquisa em Administração. $3^{a}$. ed. São Paulo: Atlas, 2012.

RUSSO, M.; FOUTS, P. A Resource-based Perspective on Corporate Environmental.

Academy of Management Journal, p. 534-559, jun 1997. ISSN 0001-4273. Disponível em: www.spell.org.br/documentos/download/34179 - Acesso em: 13 fev 2015.

TEECE, D. J. Explicating dynamic capabilities: the nature and microfoundations of (sustainable) enterprise performance. Strategic Management Journal, v. 28, n. 13, p. 13191350, dez 2007. ISSN 1097-0266. Disponível em:

http://onlinelibrary.wiley.com/doi/10.1002/smj.640/abstract - Acesso em: 03 fev 2015.

TRAMONTIN, R. Ensino Superior: uma agenda para repensar seu desenvolvimento.

Educação Brasileira, v. 18, p. 35-62, jan-jul 1998. ISSN 1413-2478.

TRIVIÑOS, A. N. S. Introdução à pesquisa em ciências sociais: a pesquisa qualitativa em educação. São Paulo: Atlas, 1987.

VERGARA, S. C. Projetos e relatórios de pesquisa em Administração. São Paulo: Atlas, 1997.

VERGARA, S. C. Universidade corporativa: a parceria possível entre empresa e universidade tradicional. Revista de Administração Pública, v. 34, n. 5, p. 181-188, set-out 2000. ISSN 0034-7612.

WERNERFELT, B. A Resource Based View of The Firm. Strategic Management Journal, 1984. ISSN 1097-0266. Disponível em: https://faculty.fuqua.duke.edu/ moorman /MarketingStrategy-Seminar-2013/Session\%201/Wernerfelt.pdf - Acesso em 25 jan. 2015. 